\title{
Espaços Verdes Urbanos e as Percepções Globais dos Serviços Ecossistêmicos à Luz da Tecnologia
}

\section{Urban Green Spaces and Global Perceptions of Ecosystem Services} in the Light of Technology Espacios Verdes Urbanos y las Percepciones Globales de los Servicios Ecosistémicos a la Luz de la Tecnología

\author{
SAMPAIO, Vitor Hugo de Goes ${ }^{1}$ \\ BAPTISTA, Gustavo Macedo de Mello² \\ 1Programa de Pós-Graduação da Faculdade de Arquitetura e Urbanismo, Faculdade de Arquitetura e Urbanismo, \\ Universidade de Brasília, Brasília, Brasil. \\ vitorsampaio.engambiental@gmail.com \\ ORCID ID: 0000-0001-6514-664X \\ 2Instituto de Geociências da Universidade de Brasília, Universidade de Brasília, Brasília, Brasil. \\ gmbaptista@gmail.com \\ ORCID ID: 0000-0002-1973-2725
}




\title{
Resumo
}

Intensos processos de extensão e modificação urbana refletiram na normalização da habitabilidade de ambientes adversos, hostis e/ou insalubres e alterações significativas dos serviços ecossistêmicos. Por isso é urgente a transição da sociedade e dos ambientes urbanos para um modelo pautado nos princípios da sustentabilidade. $\mathrm{O}$ trabalho tem como objetivo analisar em escala global a importância dos serviços ecossistêmicos para a sustentabilidade das cidades e seus habitantes e compreender o uso de diferentes metodologias para a percepção, o planejamento e a gestão desses serviços em grandes centros urbanos. A metodologia consistiu em análise bibliométrica a partir do uso da plataforma SCOPUS, com o mecanismo de busca definido por artigo e reviewe trabalhos publicados em inglês ou espanhol. A gestão bibliográfica foi realizada no software Mendeley e as redes semânticas foram estabelecidas no VOSviewer. Observou-se um grande volume de trabalhos publicados, com destaque para Estados Unidos, China e Reino Unido, assim com Alemanha e Austrália. Foi constatado também a presença de múltiplas metodologias de análise que vão desde aptidão lúdica ao uso de realidade virtual e imagens de satélite.

Palavras-Chave: Serviços Ecossistêmicos, Áreas Verdes Urbanas, Expansão Urbana, Desenvolvimento Sustentável, Redes Semânticas.

\begin{abstract}
Intense urban extension and modification processes reflected in the normalization of adverse, hostile and/or unhealthy environments and significant changes in ecosystem services. That is why there is an urgent need for the transition of society and urban environments to a model based on the principles of sustainability. The work aims to analyze on a global scale the importance of ecosystem services for the sustainability of cities and their inhabitants and to understand or use different methods for the perception, planning and management of these services in large urban centers. A methodology consisted of bibliometric analysis using the SCOPUS platform, with the search engine defined by article and review and works published in English or Spanish. Bibliographic management was performed using Mendeley software and as semantic networks were used in VOSviewer. Observe a large volume of published works, with emphasis on the United States, China and the United Kingdom, as well as Germany and Australia. It was also found the presence of several analysis methodologies, ranging from musical exploration to the use of virtual reality and satellite images.
\end{abstract}

Key-Words: Ecosystem Services, Urban Green Areas, Urban Expansion, Sustainable Development, Semantic Networks.

\section{Resumen}

Intensos procesos de expansión y modificación urbanística reflejaron en la normalización de la habitabilidad en ambientes adversos, hostiles y / o insalubres y cambios significativos en los servicios ecosistémicos. Es por ello que urge la transición de la sociedad y los entornos urbanos hacia un modelo basado en los principios de la sostenibilidad. El trabajo tiene como objetivo analizar en escala global la importancia de los servicios ecosistémicos para la sostenibilidad de las ciudades y sus habitantes y comprender el uso de diferentes metodologías para la percepción, planificación y gestión de estos servicios en los grandes centros urbanos. La metodología consistió en el análisis bibliométrico mediante el uso de la plataforma SCOPUS, con el buscador definido por artículo y revisión y trabajos publicados en inglés o español. La gestión bibliográfica se realizó en el software Mendeley y sus redes semánticas en VOSviewer. Hubo un gran volumen de trabajos publicados, con énfasis en Estados Unidos, China y Reino Unido, además de Alemania y Australia. También se constató la presencia de múltiples metodologías de análisis, que van desde la aptitud lúdica hasta el uso de la realidad virtual y las imágenes de satélite.

Palabras clave: Servicios Ecosistémicos, Áreas Verdes Urbanas, Expansión Urbana, Desarrollo Sostenible, Redes Semánticas. 


\section{Introdução}

A terra urbana passou por intensos processos de extensão e modificação nas últimas décadas, a ponto de se tornar um dos mais dinâmicos e importantes ambientes modificados por ações antrópicas. Não obstante às significativas transformações fisionômicas das cidades, essas áreas devem continuar o seu processo de expansão global pelos próximos anos (SETO et al., 2012; ZHOU et al., 2019). Quando expresso em números, esse processo representa uma área equivalente a 20.000 campos de futebol americano de expansão diária e um incremento semanal de aproximadamente 1 milhão de habitantes (UNITED NATIONS, 2018; SETO et al., 2011). Por conseguinte, tem-se um crescimento exponencial nas demandas por novos serviços, modos de transportes, matérias-primas para fabricação de bens (assim como o rápido uso e descarte dos mesmos), processamento de informações e dados com inevitáveis e significativos impactos negativos ao meio ambiente (ELLIOT et al., 2019).

A exposição desmedida a níveis prejudiciais de radiação ultravioleta e/ou aos diferentes tipos de poluição influencia diretamente a saúde humana, tendo como consequência o maior risco de morbimortalidade ou o desenvolvimento de doenças respiratórias e cardiovasculares causado pela presença de dióxido de enxofre $\left(\mathrm{SO}_{2}\right.$ ), monóxido de carbono (CO) e/ou material particulado em suspensão no ar (CHIEN et al., 2016; JERRETT et al., 2013). Com isso, tem-se um aumento na demanda por serviços de saúde. No Brasil, por exemplo, os gastos com saúde envolvendo consultas médicas, realização de exames, tratamentos e internações deve chegar a 10,7\% do PIB até 2050 (KILSZTAJN et al., 2013).

Os intensos processos de urbanização, em sua maioria, refletem negativamente o modo de vida da população, trazendo alterações significativas aos serviços ecossistêmicos ou à vegetação primitiva (LOBODA e ANGELIS, 2005). Serviços ecossistêmicos podem ser definidos como processos, condições, bens e serviços fornecidos pelos ecossistemas naturais e suas espécies para manter e atender às necessidades humanas, tendo como suprimento básicos os fatores biofísicos e as modificações no tempo e espaço (ZHENG et al., 2020; TAVARES et al., 2019). Isto posto, evidencia-se a urgência na transição da sociedade e dos ambientes urbanos para um modelo pautado nos princípios da sustentabilidade, sem deixar de lado a formulação de políticas públicas que vão além da gestão única da paisagem urbana (PULIGHE et al., 2016). Nesse sentido, os estudos sobre serviços ecossistêmicos e a disponibilidade de áreas verdes estão em ascensão e majoritariamente sendo relacionados à questão ambiental nas cidades.

A estrutura vegetativa e o modo como ela fornece seus serviços, tal como os fatores responsáveis pela sua extensão nas cidades, são diversos (RICHARDS et al., 2019). Ao passo que as sociedades dominam os processos naturais a partir da urbanização planetária (BRENNER, 2014), é fundamental encorajar representantes, tomadores de decisão, lideranças políticas, arquitetos, urbanistas, paisagistas e planejadores em geral a considerar a presença de outras espécies e o compartilhamento do espaço em nível local, nacional e internacional (MALLER, 2018; RUPPRECHT, 2017). Vários acordos e estruturas internacionais destacaram a necessidade de mais informações e estudos sobre as áreas urbanas e suas relações (ZHU et al., 2019). Assim sendo, o trabalho tem como objetivo analisar em escala global a importância dos serviços ecossistêmicos para a sustentabilidade das cidades e seus habitantes e compreender o uso de diferentes metodologias para a percepção, o planejamento e a gestão desses serviços em grandes centros urbanos.

\section{Material e Métodos}

Para que seja possível o desenvolvimento de novos conhecimentos faz-se necessário o tratamento em termos de coleta e seleção de informações, ou seja, a definição critérios confiáveis para reduzir a subjetividade na escolha das publicações, além de permitir a criação de protocolos replicáveis e indicadores importantes. Deste modo, utiliza-se a Revisão Sistemática e técnicas de Análise Bibliométrica (MEDEIROS et al., 2015). 
Revisão Sistemática, por Sampaio e Mancini (2007), representa o formato de pesquisa que tem como princípio uma fonte de dados literários para temas específicos. A abordagem adotada teve como norte as etapas propostas do Sampaio e Mancini (2007) disponíveis no Quadro 1 bem como o Checklist do processo de pesquisa proposto por Medeiros et al. (2015) disponível no Quadro 2. Vale ressaltar ainda que a caracterização dos estudos deve ser precisa e pragmática (GOUGH et al., 2012) adequada e coerente para contribuir com uma leitura crítica da temática em questão (NEVES et al., 2018).

Quadro 1: Etapas para a execução da Revisão Sistemática.

\begin{tabular}{|rl|l|}
\hline Etapa & Descrição \\
\hline 1) & Definição da pergunta & O que se deseja pesquisar? \\
\hline 2) & Busca da evidência & Etapa realizada em bases de dados eletrônicas. \\
\hline 3) & Revisão e seleção dos estudos & $\begin{array}{l}\text { Estabelecimento de critérios para verificação da } \\
\text { validade dos estudos. }\end{array}$ \\
\hline 4) Análise da qualidade metodológica & $\begin{array}{l}\text { Agrupamento de artigos de acordo com suas } \\
\text { semelhanças de maneira a evitar conclusões } \\
\text { tendenciosas. }\end{array}$ \\
\hline 5) & Apresentação dos resultados & Redação dos resultados. \\
\hline \multicolumn{2}{|c|}{ Fonte: adaptado de Sampaio e Mancini (2007) apud. Medeiros et al., (2015). }
\end{tabular}

Quadro 2: Checklist para elaboração de pesquisa de revisão sistemática e análise bibliométrica.

\begin{tabular}{|c|c|c|c|}
\hline Etapa & Sub-Eta & pa & \multirow{2}{*}{$\begin{array}{l}\text { Descrição } \\
\text { O que se pretende pesquisar? } \\
\text { Qual o tema da pesquisa? }\end{array}$} \\
\hline \multirow[t]{7}{*}{ Revisão Sistemática } & 1) Determinação dos & $\begin{array}{l}\text { Determinação dos } \\
\text { objetivos }\end{array}$ & \\
\hline & 2) & $\begin{array}{ll}\text { Determinação } & \text { do } \\
\text { descritor de busca }\end{array}$ & $\begin{array}{l}\text { Termos componentes do } \\
\text { descritor em busca e seleção de } \\
\text { operadores lógicos para } \\
\text { integração (exemplos: OR, AND, } \\
\text { NOT, AND NOT). }\end{array}$ \\
\hline & & $\begin{array}{l}\text { Escolha da base de } \\
\text { dados }\end{array}$ & $\begin{array}{lrr}\text { Disponível no } & \text { Portal } & \text { de } \\
\text { Periódicos da } & \text { CAPES } \\
\text { (Coordenação } & & \text { de } \\
\text { Aperfeiçoamento de Pessoal de } \\
\text { Nível Superior). }\end{array}$ \\
\hline & & $\begin{array}{l}\text { Realização da busca a } \\
\text { partir do descritor }\end{array}$ & $\begin{array}{l}\text { Busca nas bases selecionadas } \\
\text { na sub-etapa (3). }\end{array}$ \\
\hline & 5) & Filtros e critérios & Horizonte, idiomas e outros. \\
\hline & 6) & $\begin{array}{l}\text { Uso do EndNote (OBS: } \\
\text { na pesquisa em } \\
\text { questão optou-se pelo } \\
\text { uso do Mendeley, } \\
\text { também da editora } \\
\text { Elsevier) }\end{array}$ & $\begin{array}{l}\text { Uso de um software gerenciados } \\
\text { de bibliografias para publicação } \\
\text { de artigos científicos. Organizar } \\
\text { por título, palavras-chave e } \\
\text { resumo. }\end{array}$ \\
\hline & & $\begin{array}{ll}\text { Sistematização da } \\
\text { bibliografia }\end{array}$ & $\begin{array}{l}\text { Planilha dos artigos restantes da } \\
\text { sub-etapa (6). }\end{array}$ \\
\hline Análise Bibliométrica & & $\begin{array}{ll}\text { Exposição } & \text { dos } \\
\text { indicadores } & \\
\text { bibliométricos } & \\
\end{array}$ & $\begin{array}{l}\text { Seleção dos indicadores } \\
\text { bibliométricos pertinentes a sub- } \\
\text { etapa (1). }\end{array}$ \\
\hline & & Resultados & $\begin{array}{l}\text { Dados bibliométricos dos artigos } \\
\text { selecionados expressos por } \\
\text { meio de tabelas, gráficos, etc. }\end{array}$ \\
\hline Resultados Final & 10) & Relatório & $\begin{array}{l}\text { Texto com as análises e } \\
\text { interpretações do(s) autor(es). }\end{array}$ \\
\hline
\end{tabular}

Foram identificados, inicialmente, diversos estudos que atenderam ao escopo da pesquisa. Do mesmo modo, as abordagens teóricas e metodológicas, considerando pesquisas a nível mundial, também foram atendidas. Em seguida foi determinado um descritor de busca. $\mathrm{O}$ banco de dados utilizados para a análise bibliométrica desta investigação foi a plataforma SCOPUS, base de dados pertencente a editora Elsevier. A escolha ocorreu devido à sua relevância segundo uma pesquisa preliminar no "Periódico Capes". A plataforma, uma das maiores e mais importantes do mundo, indexa o conteúdo de aproximadamente 24.600 títulos e 5.000 editores, rigorosamente selecionados e examinados, e gera 
resultados precisos para a tomada de decisões, ações e resultados (ELSEVIER, 2020). É importante destacar que todas as buscas foram feitas a partir do acesso remoto via CAFe; A opção permite o acesso ao conteúdo assinado do Portal de Periódicos pela Universidade de Brasília. Para evitar resultados superficiais e/ou genéricos, normalmente obtidos em buscas rápidas, determinou-se um algoritmo de busca com um dos Operadores Lógicos Booleanos.

Os termos IMPORTANCE, GREENSPACES e MEGACITIES foram adotados, todos conectados pelo operador de interseção booleano AND (sua função consiste em restringir a pesquisa, de forma a obter a interseção entre os termos pesquisados). A pesquisa foi realizada na opção de busca article, title, abstract, keywords. É importante destacar que a plataforma oferece outras opções de busca relacionadas a partes específicas de um documento (all fields, authors, first author, affiliation, language, DOI, entre outros). Tais estratégias resultaram em um refinamento de um total de 11.800 resultados encontrados para 89 trabalhos. De posse do resultado encontrado, foram aplicados outros filtros de busca. O período de publicação determinado foi de 2018 a 2020, para entender o que de melhor e mais moderno está sendo aplicado nos estudos sobre a importância dos serviços ecossistêmicos bem como a percepção das áreas verdes nos ambientes urbanos. O tipo de documento foi Article e Review, enquanto os idiomas selecionados foram o inglês e espanhol. 57 trabalhos publicados foram encontrados.

Foram usados também os termos ECOSYSTEM e SERVICES conectados pelo operador booleano AND no formato de busca simples também na plataforma SCOPUS. A intenção da segunda pesquisa consistiu em analisar a evolução temporal das publicações e os países que mais se destacaram nos estudos. $O$ período estabelecido foi de 1972 a 2020, tendo em vista que a Primeira Conferência Mundial sobre o Homem e o Meio Ambiente, realizada pela ONU (Organização das Nações Unidas) em Estocolmo, ocorreu entre 5 e 16 de junho de 1972 (BOFF, 2015).

Os trabalhos selecionados foram exportados em formato csv incluindo as informações das citações (autores, título do documento, ano da publicação, volume, páginas, tipos de acesso, entre outros), assim como resumo e palavras-chaves. A gestão bibliográfica foi realizada por meio do software Mendeley, da Elsevier. Consiste em um gerenciador de referências para auxiliar o pesquisador na organização dos estudos, integrar uma rede social acadêmica, bem como descobrir pesquisas mais recentes (ELSEVIER, 2020). A ferramenta possibilitou uma leitura objetiva dos dados bibliográficos obtidos na base SCOPUS de modo a caminhar em direção ao objeto de estudo. Ao final da etapa de triagem e análise de acordo com os critérios de elegibilidade, 36 artigos se adequaram ao objeto de estudo.

Por fim, os dados bibliográficos foram carregados também no software VOSviewer para estabelecimento das redes semânticas. O tipo de análise foi de coautoria, com método de contagem fracionada e as unidades de análises para definição das redes foram estabelecidas por autores e instituições mais relevantes e países que mais publicaram a "importância de espaços verdes em megacidades".

\section{Resultados e Discussão}

Há décadas as áreas verdes e seus serviços ecossistêmicos são relacionados ao ambiente urbano. Entre 1863 e 1903, por exemplo, Frederick Law Olmsted, nos Estados Unidos, já destacava a inclusão de parque urbanos ao planejamento espacial e os relacionava aos princípios ecologicamente sensíveis, como também Jaqueline Tyrwhitt, entre 1905 e 1983, e Patrick Geddes, em 1915, acreditavam na combinação da ecologia e do planejamento urbano (PARRIS et al., 2018). Seguindo a mesma percepção, Hayward e Weitzer, em 1984, defendiam os parques urbanos como provedores de serviços ecossistêmicos culturais e oportunidades de lazer (ZHENG et al., 2020).

Como exemplos de estudos mais recentes, Jack Ahern e seu modelo $A B C$ relacionava funções abióticas, bióticas e culturais nos ambientes urbanos (AHERN, 2007). Hunter e Luck (2015) destacaram os parques urbanos como uma das formas mais importantes de espaço verde, contribuindo para a sustentabilidade 
urbana e fornecendo uma ampla gama de serviços ecossistêmicos (YAN et al., 2018). Mas afinal, como são classificados os serviços ecossistêmicos? Geralmente são classificados como serviços de provisão, como alimentos e matérias-primas, regulação, como as florestas, suporte, exemplificado pelos ciclos da água e dos nutrientes, e cultural, que consiste nas interações estéticas e saudáveis da natureza (HAINES-YOUNG e POTSCHIN-YOUNG, 2018; COSTANZA et al., 1997).

Ao analisarmos a evolução temporal das publicações sobre serviços ecossistêmicos no mundo representado pela Figura 1, assim como a rede semântica da Figura 2, percebemos o predomínio disparado dos Estados Unidos com quase 15.000 de um total de 47.050 documentos publicados na plataforma SCOPUS. Na sequência aparecem Reino Unido, com pouco mais de 5.900 publicações, China (5.788), Alemanha (4.466) e Austrália (3.362). Vale destacar que o Brasil não aparece sequer no topo dos 15 principais países. Ao verificarmos o gráfico presente na Figura 3, que traz o número de publicações por ano, notamos um número discreto de publicações entre 1972 e 1997 . Vale ressaltar que nesse período tivemos a Primeira Conferência Mundial sobre o Homem e o Meio Ambiente, em 1972 em Estocolmo, o surgimento da Comissão Mundial sobre Meio Ambiente e Desenvolvimento, em 1987, com fechamento em 1987 após a publicação do Relatório Brundtland, cujo título é "Nosso futuro comum". Ainda nesse período, mais precisamente em 1992, no Rio de Janeiro, aconteceu a Conferência das Nações Unidas sobre Meio Ambiente e Desenvolvimento, conhecida também por Cúpula da Terra. Neste último encontro, foram publicados diversos documentos importantes, com destaque para a Agenda $21 \mathrm{e}$ a Carta do Rio de Janeiro que afirma que todos indivíduos devem cooperar para a erradicação da pobreza como requisito básico para o desenvolvimento sustentável. Por fim, em 1997, ocorreu o Fórum Rio+5 (BOFF, 2015).

Figura 1: Número de publicações de documentos científicos na plataforma SCOPUS, por país, entre 1972 e 2020.

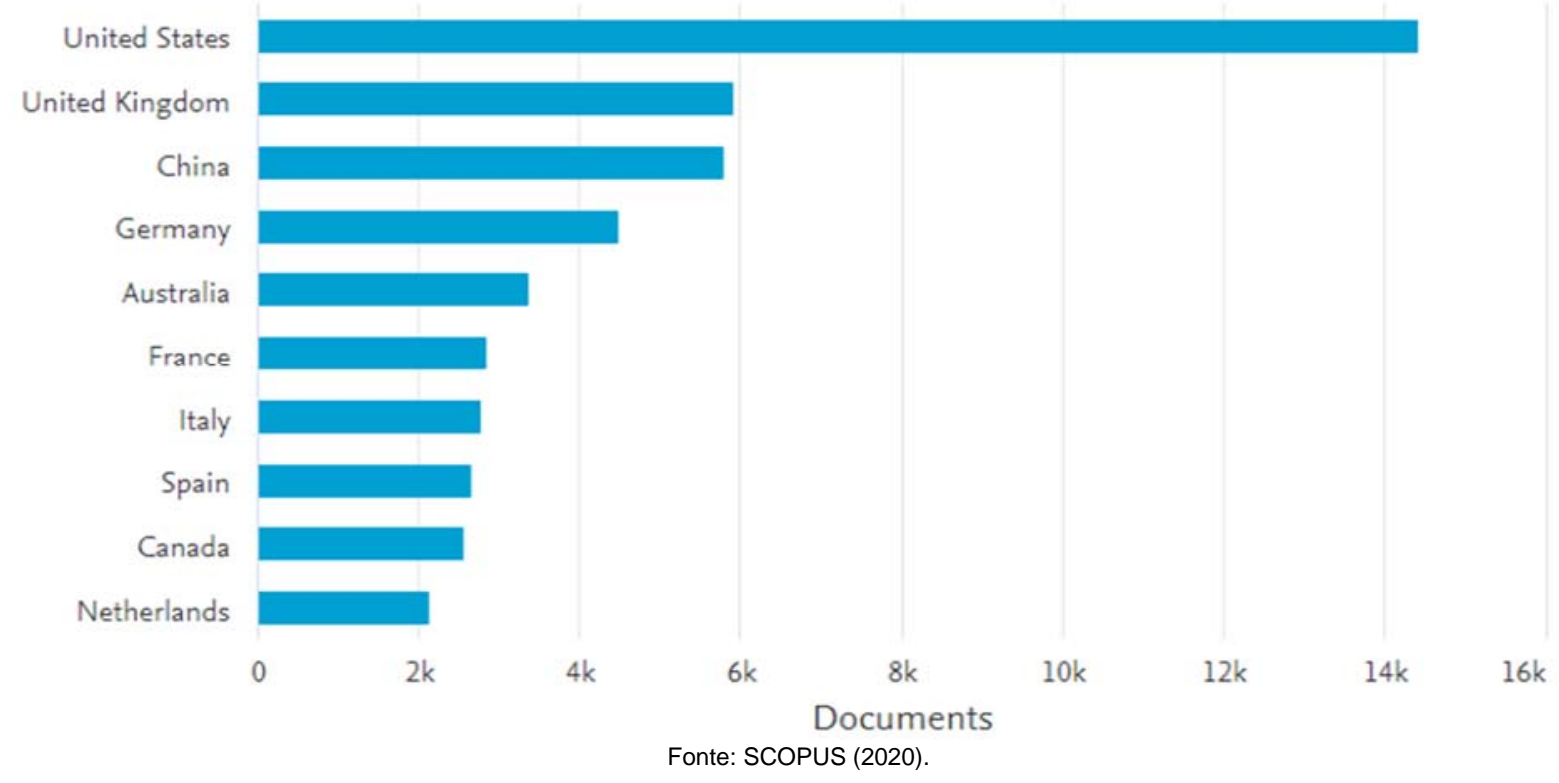


Figura 2: Densidade dos países que mais publicaram artigos no mundo envolvendo serviços ecossistêmicos. Os círculos mais intensos representam os países mais importantes em termos de publicação.

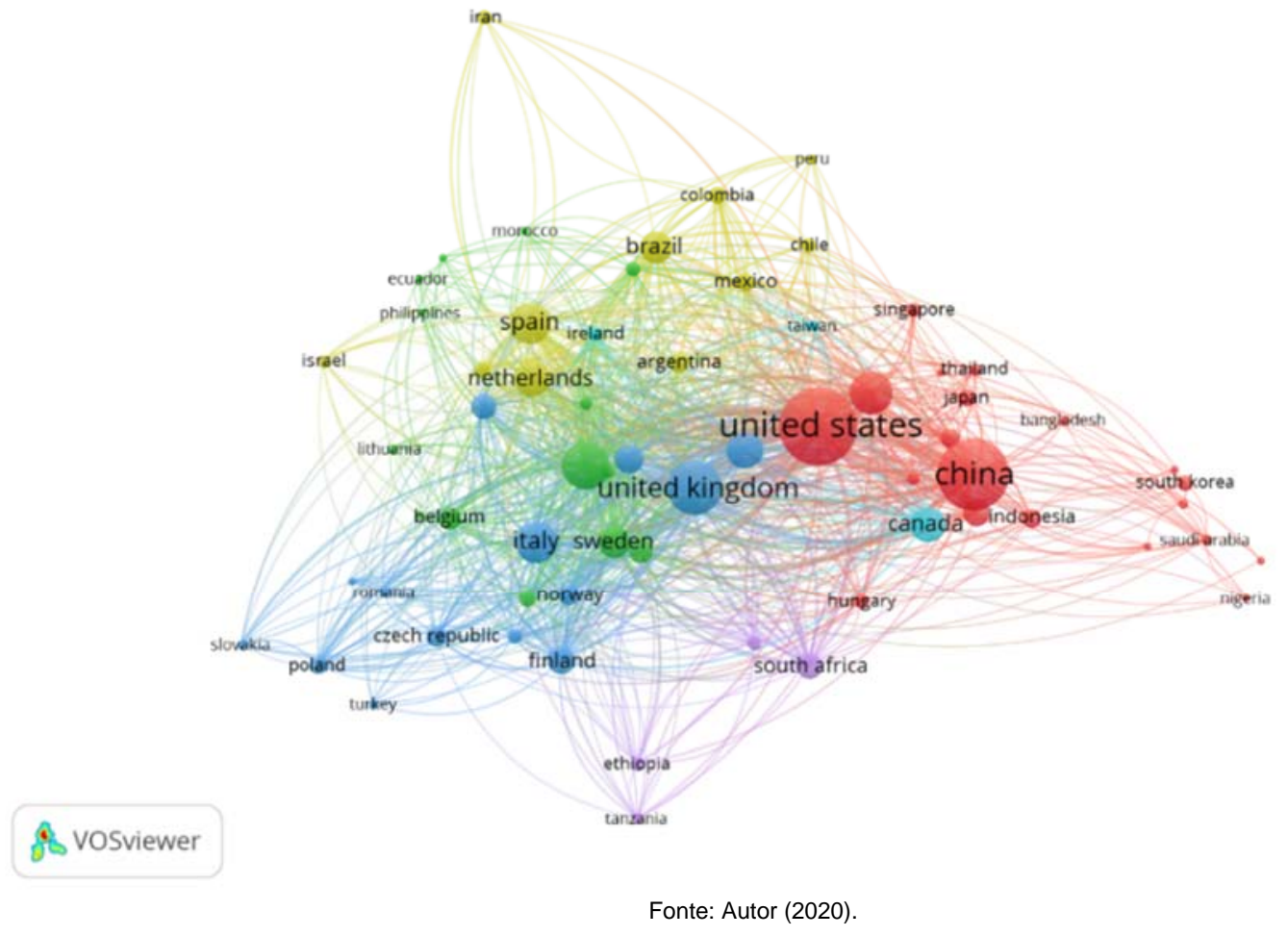

Seguindo a análise da Figura 3, nota-se um crescimento discreto entre 1998 e 2004. O período foi marcado pela Cúpula da Terra sobre a Sustentabilidade e Desenvolvimento, acontecido entre 26 de agosto e 4 de setembro de 2002, em Johanesburgo. O evento contou com a representação de 150 nações, assim como a presença de cientistas, ambientalistas, entusiastas e corporações. Para Boff (2015), enquanto na Eco-92 tinha-se um ecossistema de cooperação embalado pela queda do Muro de Berlim, em Johanesburgo o clima amistoso fora perdido. Houveram, na verdade, decisões unilaterais das grandes potências mundiais apoiadas pelos importantes produtores de petróleo. $\mathrm{O}$ saldo positivo para todos as conferências mundiais da ONU foi o fortalecimento da expressão "desenvolvimento sustentável" e a conscientização humana para as questões ambientais. Seguindo essa tendência, entre 2005 e 2019, tivemos um crescimento exponencial de pesquisas científicas na temática, com pico máximo em 2019 e um total de 6171 documentos publicados. Em 2020, até o momento, nota-se uma queda quase que pela metade no número de publicações em relação ao ano passado, um total de 3476 documentos presentes na Plataforma até o momento da pesquisa. Esse déficit pode ser justificado pela dificuldade de acesso aos grandes centros de pesquisa, falta de material ou equipamento de suporte e, principalmente, pelo isolamento social provocado pela pandemia da Covid-19. Além disso, pesquisadores, universidades e sociedade em geral voltaram as atenções para solução ou entendimento no novo quadro sanitário vivenciado. 
Figura 3: Número de publicações de documentos científicos na plataforma SCOPUS, por ano, entre 1972 e 2020.

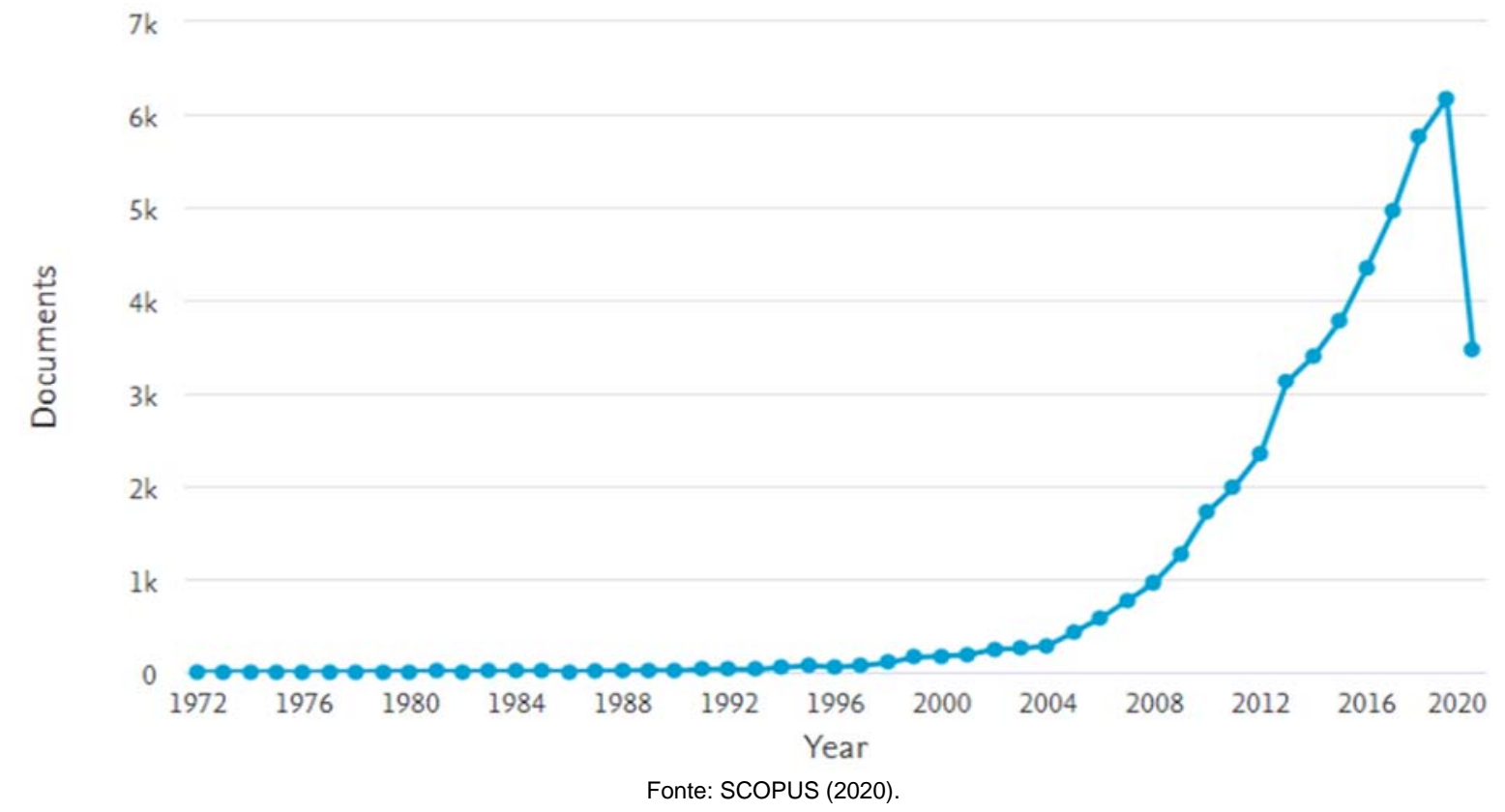

Parques urbanos, por exemplo, fornecem significativos serviços ecossistêmicos culturais; estes por sua vez, definidos como benefícios não materiais (cognição, recreação, estética e outros) às pessoas. Dentre os benefícios destacam-se a redução do estresse, restauração de capacidades mentais, redução de problemas relacionados à saúde física e obesidade, assim como a redução nos riscos de doenças em geral, a promoção de relações sociais e o desenvolvimento comunitário harmonioso (ZHENG et al., 2020; WANG e QIU, 2018). A arborização de vias públicas também é peça cada vez mais importante para as cidades, que quando somada aos parques possibilita o dimensionamento do bem-estar e a qualidade de vida no ambiente urbano.

Lima (2007) e Bargos (2010) retrataram a importância das áreas verdes para a qualidade ambiental em São Paulo, enquanto Coq-Huelva e Asián-Chaves (2019) analisaram as principais características e as políticas relacionadas ao paradigma da sustentabilidade na Cidade do México, em Lima e Santiago do Chile. McDonald, Kareiva e Forman (2008) estimaram que 420 espécies presentes na Lista Vermelha de Espécies Ameaçadas (Red List of Threatened Species) da IUCN (International Union for Conservation of Nature) foram impactadas pela urbanização. Já Teza e Baptista (2015) quantificaram o processo de supressão vegetal e a consequente redução da área de sequestro florestal de carbono, reflexos da expansão urbana na região metropolitana de Brasília.

Em artigo publicado no Journal of Environmental Horticulture (JEH), Hall e Dickson (2011) resumiram os benefícios ambientais, econômicos, sociais e de saúde que as plantas proporcionam quando estas estão em interação direta com as pessoas. Os resultados encontrados reforçam o que fora mencionado, como redução da ansiedade e do estresse, recuperação do déficit de atenção, melhoria em quadros de depressão e mitigação do transtorno do estresse pós-traumático, maior produtividade, felicidade e satisfação com a vida, assim como a melhoria da autoestima. De fato, a quantidade de espaços verdes em áreas residenciais está positivamente relacionada à saúde geral dos seus habitantes. A presença de espaço verde na vizinhança ou o acesso a um jardim e até mesmo a exposição a cenas naturais podem promover melhorias significativas na vida das pessoas (PARK et al., 2017).

Nessa perspectiva, Zheng et al. (2020) investigaram, sob a ótica da ecologia e por meio de um sistema de indicadores e avaliações perceptivas, a relação entre os serviços ecossistêmicos culturais fornecidos pelos parques urbanos e as percepções sensitivo-sensoriais dos seus visitantes sobre os mesmos. Com 
base nos resultados avaliativos de satisfação, foram sugeridas melhores práticas de design e gerenciamento de parques urbanos a fim de promover o bem-estar comum (YAN et al., 2017). Ao passo que Tran, Helmus e Behm (2020), em estudo aplicado na Filadélfia, Estados Unidos, propôs o modelo de planejamento urbano sustentável GIST (Green Infrastructure Space and Traits), que consiste em avaliar e maximizar, a partir da seleção de áreas prioritárias e de plantas que maximizem os benefícios à população, a multifuncionalidade de infraestruturas verdes.

Parris et al. (2018) fizeram uso de um conjunto de metáforas relacionais para ajudar a entender as decisões urbanas e promover o crescimento da biodiversidade. Nesse contexto, foram apresentados sete princípios ecológicos como uma série de alvos para conectar metaforicamente o humano e o mais do que humano nas cidades e preservar características de alta biodiversidade na paisagem urbana, como a preservação de linhas de drenagem natural dentro da perspectiva do desenvolvimento de baixo impacto. Sacchelli e Favaro (2019), de forma a classificar a aptidão lúdica a nível espacial, desenvolveram a análise de um parque urbano da cidade de Florença (Itália) baseada nas percepções integradas dos seus sons e suas paisagens. Uma abordagem inovadora fora aplicada de modo a fortalecer o apoio à decisão bem como o gerenciamento dos serviços ecossistêmicos culturais nesses ambientes. Houve uma mescla de tecnologias e abordagens para elicitar visitas às florestas urbanas, como o uso de regressão linear múltipla, informações geográficas e métodos geoestatísticos (Google Street View) para a espacialização e mapeamento do local, realidade virtual (VR) para facilitar a representação recreativa com a reprodução de trilhas sonoras de pássaros, por exemplo, e representação de áreas de recuperação de estresse, além de parâmetros psicoacústicos e abordagem de código aberto.

As áreas verdes atuam ainda no fornecimento de serviços ecossistêmicos urbanos, como a captura de carbono, redução da poluição do ar, mitigação das ilhas de calor, mitigação de enchentes, deslizamentos, chuvas ácidas, bem como trazem resultados benéficos na composição atmosférica, no equilíbrio do solo, no tempo e regulação dos microclimas urbanos (ROSSATTO et al., 2018). Oferecem instalações recreativas e de lazer com funções educativas, locais de refúgio às ocupações cotidianas, além de serem consideradas as principais fontes de contato com a natureza nos ambientes urbanos e suporte à biodiversidade (ELMQVIST et al., 2015; WILLIS e PETROKOFSKY, 2017; BENINDE et al., 2015). Por isso os ambientes urbanos são pontos focais de estudo, oferta e demanda desses serviços. A incorporação em quantidade, qualidade e diversidade dos serviços ecossistêmicos, garante a resiliência econômica, social e ecológica nas cidades (TAVARES et al., 2019; MCPHEARSON et al., 2015).

Definir e estudar o espaço verde urbano não é tarefa fácil, muito embora historicamente tenha sido amplamente avaliado. Mesmo que as pesquisas envolvendo a temática se dissipe pelos vários tipos de espaços, há um ponto em comum entre elas, a acessibilidade. A disparidade de acesso aos espaços verdes em diferentes grupos socioeconômicos é quase unânime entre os pesquisadores. Zhou e Kim (2013), por exemplo, concluíram por meio de imagens aéreas que minorias raciais e étnicas dispõem de menos copa de árvores nas regiões que vivem. Landry e Chakraborty (2009), por sua vez, apontaram que os bairros com uma proporção maior de afro-americanos e locatários apresenta menor taxa de cobertura de árvores. Nessa perspectiva, Wang e Qu (2018) investigaram e concluíram que bairros com maior renda também têm maior número de árvores plantadas nos parques.

Para a Organização Mundial da Saúde (OMS), as cidades devem dispor de, no mínimo, $9 \mathrm{~m}^{2}$ de áreas verdes urbanas por habitante (COQ-HUELVA e ASIÁN-CHAVES, 2019). No estudo de Coq-Huelva e Asián-Chaves (2019), Santiago do Chile apresentou uma média de 3,2 $\mathrm{m}^{2}$ de área verde por habitante (análises apontam resultados ainda mais impressionantes, como 1,6 $\mathrm{m}^{2}$ de área verde por habitante), Lima $3 \mathrm{~m}^{2}$ por habitante, enquanto de a Cidade do México apresentou $15,1 \mathrm{~m}^{2}$. Todavia, essa estimativa pode ser tendenciosa por incluir jardins em áreas particulares ou áreas verdes em locais de difícil acesso, 
o que permite retomar a discussão sobre o acesso a esses ambientes. Até mesmo em zonas onde não há ocupação, raramente as áreas verdes disponíveis tenham sido fruto de planejamento (GUILLÉN, 2018). O resultado é uma fragmentação acentuada e a perda de ambientes naturais significativos que poderiam servir de habitat para diversas espécies de fauna e flora (ESCOBEDO et al., 2006).

Além da inacessibilidade e disparidade na distribuição dos cinturões verdes, algumas cidades em desenvolvimento consideram ainda anacrônicos a institucionalização desses ecossistemas. Em outras palavras, a dinâmica demográfica e a forma dos processos de acumulação de capital dificultam, em termos práticos, a conservação natural frente aos processos de expansão urbana (COQ-HUELVA e ASIÁN-CHAVES, 2019). Já nas cidades onde o crescimento urbano excedeu o esperado, as áreas verdes, por vezes, são responsabilizadas por promover a especulação imobiliária, aumentar o valor da terra em pontos comerciais e residenciais estratégicos, proporcionar o aumento nos deslocamentos e viagens com veículos automotores e intensificar congestionamentos (MA e JIN, 2018). A urbanização e o planejamento planetários privilegiam uma visão do mundo centrada no ser humano e aprofundam a crise econômica, social e ambiental no cerne do Antropoceno (HOUSTON et al., 2017).

Mapear os serviços ecossistêmicos urbanos também é tido como oportunidade para monitorar a ocorrência de áreas naturais nos ambientes urbanos e a influência sofrida por ações antrópicas, assim como verificar a variação da oferta dos serviços ecossistêmicos no tempo e espaço (TAVARES et al., 2019). A vasta disponibilidade de dados de alta resolução e softwares de acesso aberto tem reverberado no progresso SIG e desenvolvimento de novas metodologias de avaliação de paisagem (KWOK, 2018). Wró y ski et al. (2020), por exemplo, desenvolveram uma metodologia de Avaliação Quantitativa da Paisagem (Quantitative Landscape Assessment-QLA360) tendo como perspectiva o observador e seu campo de visão panorâmica de $360^{\circ}$. Os autores tomaram por base os dados obtidos da varredura a laser no ar (LiDAR) integrados ao uso de software gráfico GIS e software gráfico 3D. Para o desenvolvimento do método, assumiram requisitos importantes como independência do observador, campo de visão de 360ํㅡ, operação automática, escalabilidade e fácil apresentação dos resultados.

Transferindo, então, a análise da pesquisa para as publicações envolvendo os termos "importance", "greenspaces" e "megacities", a supremacia dos Estados Unidos continua, seguidos por China, Reino Unido, Singapura, Alemanha, Austrália e Dinamarca conforme visto na Figura 4. Foi desenvolvido também a rede semântica dos principais centros de pesquisa, destacado na Figura 5 , com destaque para o Centro de Meio Ambiente e Saúde (Centre for Environment and Health) do Imperial College London no Reino Unido, o Departamento de Arquitetura da Paisagem e Planejamento Regional (Department of Landscape Architecture and Regional Planning) da University of Massachusetts nos Estados Unidos, Centro Global de Pesquisa sobre a Limpeza do Ar (Global Centre for Clean Air Research), da University of Surrey no Reino Unido, entre outros. O desenvolvimento da rede semântica também foi aplicado para os autores dos artigos, revelados na Figura 6. 
Figura 4: Densidade dos países que mais publicaram artigos no mundo envolvendo a "importância de espaços verdes em megacidades" entre 2018 e 2020. Os círculos mais intensos representam os países mais importantes em termos de publicação.

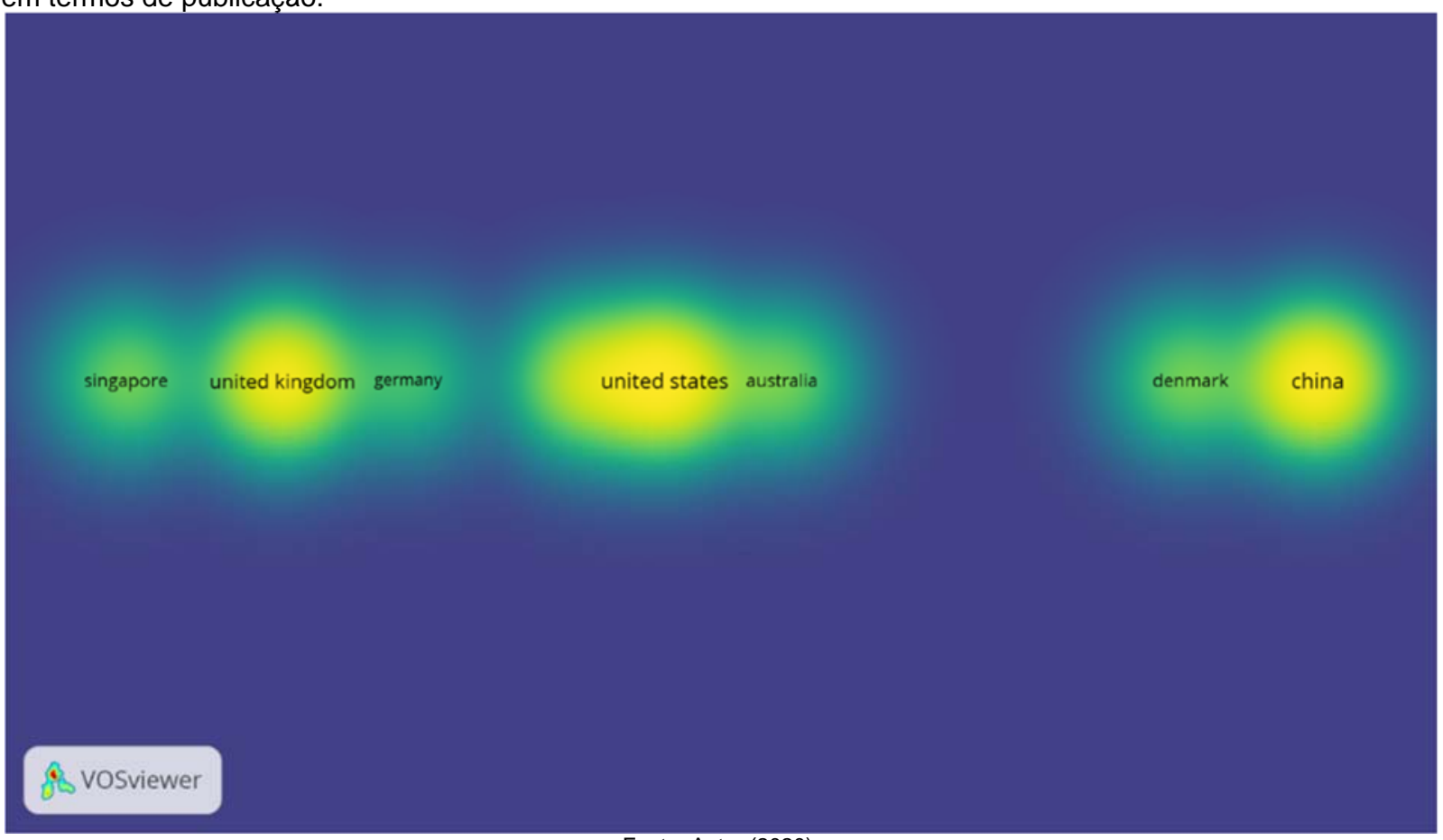

Fonte: Autor (2020).

Figura 5: Rede semântica dos principais departamentos de pesquisa no mundo envolvendo as publicações sobre a "importância de espaços verdes em megacidades" entre 2018 e 2020.

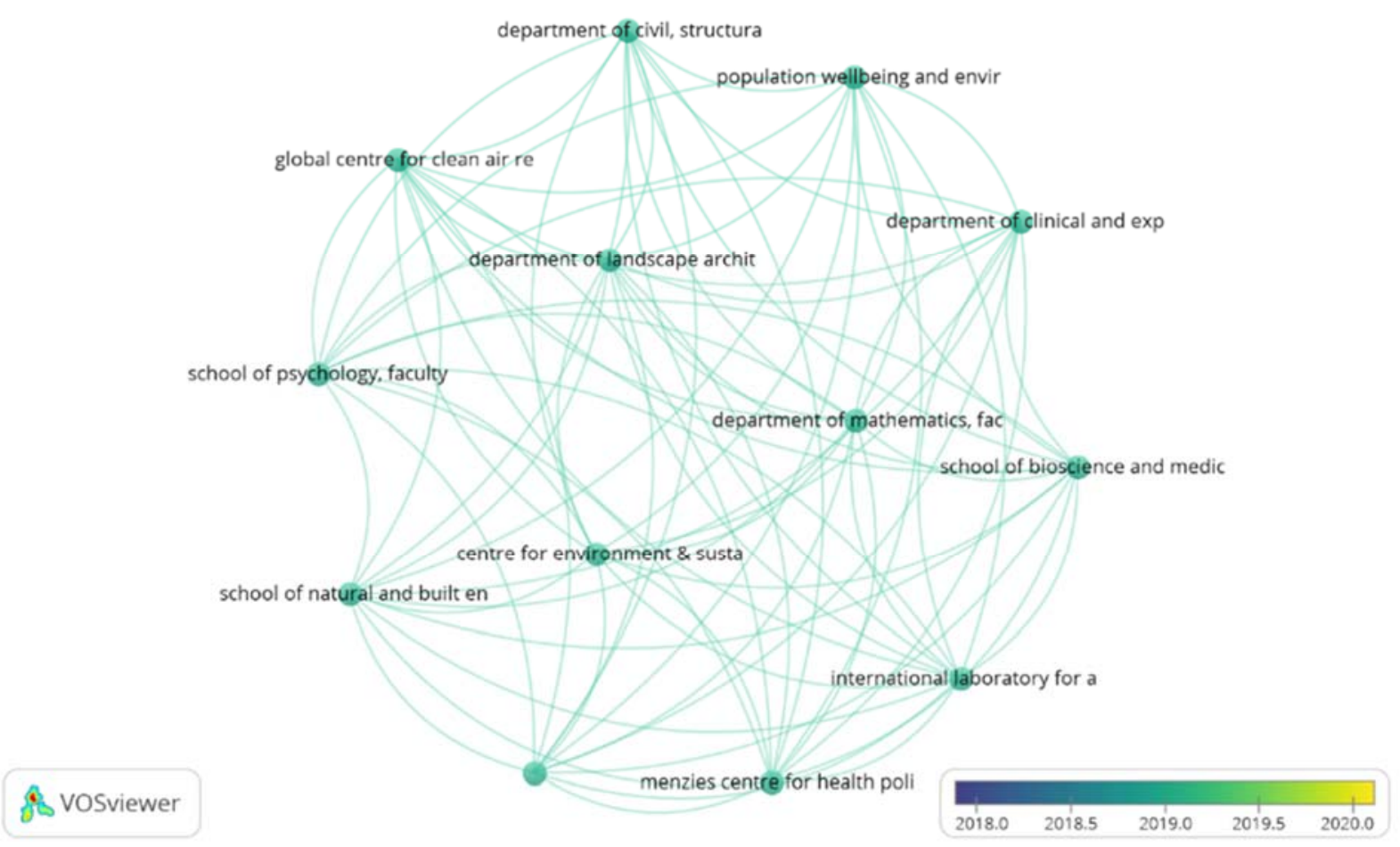

Fonte: Autor (2020). 
Figura 6: Rede semântica dos principais pesquisadores no mundo envolvendo as publicações sobre a "importância de espaços verdes em megacidades" entre 2018 e 2020.

VOSviewer

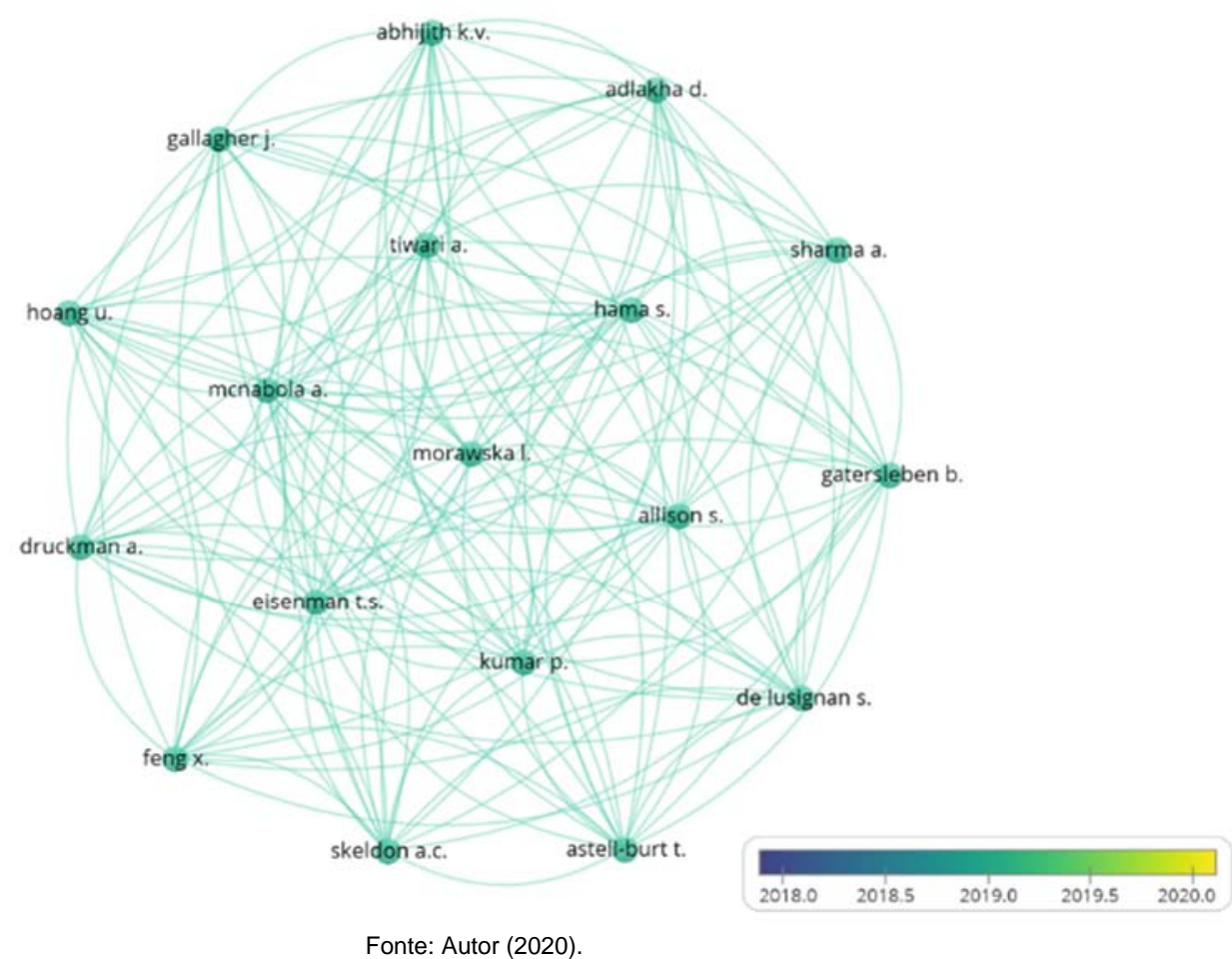

Entre os estudos desenvolvidos na China, podemos destacar Huang e Wang (2019), com a utilização de dados de sensoriamento remoto de alta resolução, dados de informações geográficas, parâmetros morfológicos urbanos $2 \mathrm{D}$ e $3 \mathrm{D}$, assim como a temperatura diurna da superfície terrestre em diferentes zonas urbanas durante o verão. A investigação ocorreu em Wuhan, megacidade da China Central, conhecida por seu clima extremo no verão. Os resultados obtidos pelos pesquisadores apontam impactos significativos da morfologia urbana da temperatura terrestre das zonas avaliadas, com destaque especial para edifícios (absorção da radiação solar, formação de fluxo de ar e geração de calor), superfícies gramíneas, arbustos e árvores. Doravante, os autores sugerem a otimização do arranjo espacial da paisagem urbana que os planejadores urbanos possam otimizar o arranjo espacial da paisagem urbana. Todavia, o estudo apresenta limitações, uma vez que é praticamente utópico reduzir o quantitativo de superfícies artificiais em grandes centros urbanos, no qual a disponibilidade de terra é cada vez mais escassa.

Ainda na China, 32 grandes cidades foram avaliadas por meio de imagens do satélite Landsat 8 , regressão múltipla e relativa e dados de pontos de interesse (Point of Interest - POI) como medida da variável de atividade humana, para recuperar a temperatura da superfície da terra e quantificar variáveis naturais da superfície (LUAN et al., 2020). As variáveis de superfície natural, Índice de Vegetação por Diferença Normalizada - Normalized Difference Vegetation Index (NDVI) e cobertura de água, e não superficial, representada pela densidade de POI, explicaram a variação considerável na temperatura de superfície. Considerando a amostra do estudo, os resultados revelaram a contribuição e a importância relativa de superfícies naturais, tanto cobertura de água quanto vegetação, para o resfriamento de aglomerações urbanas, enquanto que atividades humanas estão diretamente correlacionadas ao incremento dessas temperaturas.

\section{Conclusão}

A análise bibliométrica sobre a importância de espaços verdes nas megacidades, assim como a pesquisa e rede semântica sobre serviços ecossistêmicos revela o significativo impacto desses serviços na 
qualidade de vida das pessoas e sua relação com os ambientes construídos, assim como destaca o protagonismo que essas infraestruturas estão recebendo não apenas na ciência, como nas demandas sociais, nos debates administrativos, bem como adoção de políticas públicas. Verificou-se também a ascensão de instituições de pesquisa voltadas para a sustentabilidade e a centralidade dos estudos em países desenvolvidos, como Estados Unidos, China e Reino Unido. Esse resultado pode ser reflexo dos altos investimentos no desenvolvimento da ciência, tecnologia e inovação nesses países.

Foi constatado não apenas a significativa presença tecnológica, como as mais variadas ferramentas e metodologias voltadas para a percepção, gestão e planejamento de infraestruturas verdes, tais como o uso de realidade virtual, aptidão lúdica, regressão, SIG, imagens de satélite e NDVI. De todos os modos, as pesquisas apresentaram limitações e isso representa a vastidão de estudos e oportunidades que a temática transmite. Por isso, implementar ferramentas capazes de modelar as relações entre ambientes naturais e urbanos devem ser cada vez mais presentes, principalmente em países em desenvolvimento, onde mostrou-se uma escassez de estudos dentro das condições bibliográficas levantadas. Esse conjunto permitirá que a sociedade tome hoje, decisões conscientes para as necessidades do amanhã, fornecendo caminhos que permitam as cidades enfrentar não apenas as metas urbanas, mas também globais de desenvolvimento da sustentabilidade. Cientistas, representantes públicos ou tomadores de decisão e a sociedade civil devem sempre somar esforços para a conscientização social e ecológica de forma a encontrar caminhos fundamentais para as cidades sustentáveis.

\section{Referências}

AHERN, J.. Green Infrastructure For Cities: the spatial dimension. Cities Of The Future Towards Integrated Sustainable Water And Landscape Management, Massachusetts, v. 5, n. 24, p. 267-283, 14 maio $2007 . \quad$ Disponível em: https://pdfs.semanticscholar.org/5a5e/aa2ł3394bf3c8e5eb4400812b2d3c822eb9d.pdf?_ga=2.2766469 2.980962028.1591830888-1303282616.1591830888. Acesso em: 5 jun. 2020.

BARGOS, Danubia Caporusso. Mapeamento e Análise das Áreas Verdes Urbanas como Indicador da Qualidade Ambiental Urbana: estudo de caso de Paulínia-SP. 2010. 151 f. Dissertação (Mestrado) - Curso de Geografia, Instituto de Geociências, Universidade Estadual de Campinas, Campinas, 2010.

BENINDE, Joscha; VEITH, Michael; HOCHKIRCH, Axel. Biodiversity in cities needs space: a metaanalysis of factors determining intra-urban biodiversity variation. Ecology Letters, [s.l.], v. 18, n. 6, p. 581-592, 10 abr. 2015. Wiley. http://dx.doi.org/10.1111/ele.12427.

BOFF, Leonardo. Sustentabilidade: o que é: o que não é. 4 ed. - Petrópolis, RJ: Vozes, 2015.

CHARLES R. HALL. Economic, Environmental, and Health/Well-Being Benefits Associated with Green Industry Products and Services: a review. Journal Of Environmental Horticulture, Texas, v. 2, n. 29, p. 96-103, jun. 2011. Disponível em: https://bit.ly/2AXRa24. Acesso em: 5 jun. 2020.

CHIEN, Lung-chang; GUO, Yuming; ZHANG, Kai. Spatiotemporal analysis of heat and heat wave effects on elderly mortality in Texas, 2006-2011. Science Of The Total Environment, [s.I.], v. 562, p. 845-851, ago. 2016. Elsevier BV. http://dx.doi.org/10.1016/j.scitotenv.2016.04.042.

COQ-HUELVA, Daniel; ASIÁN-CHAVES, Rosario. Urban Sprawl and Sustainable Urban Policies. A Review of the Cases of Lima, Mexico City and Santiago de Chile. Sustainability, [s.I.], v. 11, n. 20, p. 5835, 21 out. 2019. MDPI AG. http://dx.doi.org/10.3390/su11205835.

COSTANZA, Robert; D'ARGE, Ralph; GROOT, Rudolf de; FARBER, Stephen; GRASSO, Monica; HANNON, Bruce; LIMBURG, Karin; NAEEM, Shahid; O'NEILL, Robert V.; PARUELO, Jose. The value of the world's ecosystem services and natural capital. Nature, [s.l.], v. 387, n. 6630, p. 253-260, maio 1997. Springer Science and Business Media LLC. http://dx.doi.org/10.1038/387253a0. 
ELLIOT, Thomas; ALMENAR, Javier Babí; NIZA, Samuel; PROENÇA, Vânia; RUGANI, Benedetto. Pathways to Modelling Ecosystem Services within an Urban Metabolism Framework. Sustainability, [s.I.], v. 11, n. 10, p. 2766, 14 maio 2019. MDPI AG. http://dx.doi.org/10.3390/su11102766.

ELMQVIST, T; SETÄLÄ, H; HANDEL, Sn; PLOEG, S van Der; ARONSON, J; BLIGNAUT, Jn; GÓMEZBAGGETHUN, e; NOWAK, Dj; KRONENBERG, J; GROOT, R de. Benefits of restoring ecosystem services in urban areas. Current Opinion In Environmental Sustainability, [s.l.], v. 14, p. 101-108, jun. 2015. Elsevier BV. http://dx.doi.org/10.1016/j.cosust.2015.05.001.

ELSEVIER. Sobre a solução Mendeley. 2020. Disponível em: https://www.elsevier.com/ptbr/solutions/mendeley. Acesso em: 30 maio 2020.

ELSEVIER. Sobre a solução Scopus. 2020. Disponível em: https://www.elsevier.com/ptbr/solutions/scopus. Acesso em: 30 maio 2020.

ESCOBEDO, Francisco J.; NOWAK, David J.; WAGNER, John E.; LAMAZA, Carmen Luz de; RODRÍGUEZ, Manuel; CRANE, Daniel E.; HERNÁNDEZ, Jaime. The socioeconomics and management of Santiago de Chile's public urban forests. Urban Forestry \& Urban Greening, [s.I.], v. 4, n. 3-4, p. 105114, abr. 2006. Elsevier BV. http://dx.doi.org/10.1016/j.ufug.2005.12.002.

GUILLÉN, Victor Peña. El paisaje como patrimonio edificado: una reflexión hacia el planeamiento urbano. Devenir - Revista de Estudios Sobre Patrimonio Edificado, [s.I.], v. 1, n. 2, p. 59-70, 13 ago. 2018. Universidad Nacional de Ingenieria. http://dx.doi.org/10.21754/devenir.v1i2.251.

GOUGH, David; THOMAS, James; OLIVER, Sandy. Clarifying differences between review designs and methods. Systematic Reviews, [s.I.], v. 1, n. 1, p. 1-9, 9 jun. 2012. Springer Science and Business Media LLC. http://dx.doi.org/10.1186/2046-4053-1-28.

HAINES-YOUNG, Roy; POTSCHIN-YOUNG, Marion. Revision of the Common International Classification for Ecosystem Services (CICES V5.1): a policy brief. One Ecosystem, [s.I.], v. 3, e27108, 11 jun. 2018. Pensoft Publishers. http://dx.doi.org/10.3897/oneeco.3.e27108.

HOUSTON, Donna; HILLIER, Jean; MACCALLUM, Diana; STEELE, Wendy; BYRNE, Jason. Make kin, not cities! Multispecies entanglements and 'becoming-world' in planning theory. Planning Theory, [s.l.], v. 17, n. 2, p. 190-212, 3 fev. 2017. SAGE Publications. http://dx.doi.org/10.1177/1473095216688042.

HUANG, Xin; WANG, Ying. Investigating the effects of 3D urban morphology on the surface urban heat island effect in urban functional zones by using high-resolution remote sensing data: a case study of wuhan, central china. Isprs Journal Of Photogrammetry And Remote Sensing, [s.I.], v. 152, p. 119131, jun. 2019. Elsevier BV. http://dx.doi.org/10.1016/j.isprsjprs.2019.04.010.

HUNTER, Ashlea J.; LUCK, Gary W.. Defining and measuring the social-ecological quality of urban greenspace: a semi-systematic review. Urban Ecosystems, [s.I.], v. 18, n. 4, p. 1139-1163, 19 abr. 2015. Springer Science and Business Media LLC. http://dx.doi.org/10.1007/s11252-015-0456-6.

JERRETT, Michael; BURNETT, Richard T.; BECKERMAN, Bernardo S.; TURNER, Michelle C.; KREWSKI, Daniel; THURSTON, George; MARTIN, Randall V.; VAN DONKELAAR, Aaron; HUGHES, Edward; SHI, Yuanli. Spatial Analysis of Air Pollution and Mortality in California. American Journal Of Respiratory And Critical Care Medicine, [s.l.], v. 188, n. 5, p. 593-599, set. 2013. American Thoracic Society. http://dx.doi.org/10.1164/rccm.201303-0609oc.

KILSZTAJN, S.; ROSSBACH, A.; CÂMARA, M. B. DA; CARMO, M. S. N. DO. Serviços de saúde, gastos e envelhecimento da população brasileira. Revista Brasileira de Estudos de População, v. 20, n. 1, p. 
93-108, 25 set. 2013. Disponível em: https://www.rebep.org.br/revista/article/view/306. Acesso em: 2 junho 2020.

KWOK, Roberta. Ecology's remote-sensing revolution. Nature, [s.I.], v. 556, n. 7699, p. 137-138, abr. 2018. Springer Science and Business Media LLC. http://dx.doi.org/10.1038/d41586-018-03924-9.

LANDRY, Shawn M; CHAKRABORTY, Jayajit. Street Trees and Equity: evaluating the spatial distribution of an urban amenity. Environment And Planning A: Economy and Space, [s.l.], v. 41, n. 11, p. 26512670, nov. 2009. SAGE Publications. http://dx.doi.org/10.1068/a41236.

LIMA, Valéria. ANÁLISE DA QUALIDADE AMBIENTAL NA CIDADE DE OSVALDO CRUZ/SP. 2007. 177 f. Dissertação (Mestrado) - Curso de Geografia, Programa de Pós-graduação em Geografia, Universidade Estadual Paulista, Presidente Prudente, 2007. Disponível em: <http://hdl.handle.net/11449/96691>. Acesso em: 2 junho 2020.

LOBODA, Carlos Roberto; ANGELIS, Bruno Luiz Domingos de. ÁREAS VERDES PÚBLICAS URBANAS: CONCEITOS, USOS E FUNÇÕES. Ambiência: Revista do Centro de Ciências Agrárias e Ambientais, Guarapuava, v. 1, n. 1, p.125-139, jun. 2005.

LUAN, Xiali; YU, Zhaowu; ZHANG, Yuting; WEI, Sheng; MIAO, Xinyu; HUANG, Zheng Y. X.; TENG, Shuqing N.; XU, Chi. Remote Sensing and Social Sensing Data Reveal Scale-Dependent and SystemSpecific Strengths of Urban Heat Island Determinants. Remote Sensing, [s.I.], v. 12, n. 3, p. 391, 26 jan. 2020. MDPI AG. http://dx.doi.org/10.3390/rs12030391.

MA, Mingfei; JIN, Ying. Economic impacts of alternative greenspace configurations in fast growing cities: the case of greater beijing. Urban Studies, [s.l.], v. 56, n. 8, p. 1498-1515, 11 jun. 2018. SAGE Publications. http://dx.doi.org/10.1177/0042098018770115.

MCDONALD, Robert I.; KAREIVA, Peter; FORMAN, Richard T.T.. The implications of current and future urbanization for global protected areas and biodiversity conservation. Biological Conservation, [S.L.], v. 141, n. 6, p. 1695-1703, jun. 2008. Elsevier BV. http://dx.doi.org/10.1016/j.biocon.2008.04.025.

MCPHEARSON, Timon; ANDERSSON, Erik; ELMQVIST, Thomas; FRANTZESKAKI, Niki. Resilience of and through urban ecosystem services. Ecosystem Services, [s.I.], v. 12, p. 152-156, abr. 2015. Elsevier BV. http://dx.doi.org/10.1016/j.ecoser.2014.07.012.

MEDEIROS, Ivan L. de; VIEIRA, Alessandro; BRAVIANO, Gilson; GONÇALVES, Berenice S.. Revisão Sistemática e Bibliometria facilitadas por um Canvas para visualização de informação. Revista Brasileira de Design da Informação, São Paulo, v. 12, n. 1, p. 93-110, 2015.

NEVES, Leticia de Oliveira; BERNARDINI, Sidney Piochi; RUSCHEL, Regina Coeli; MOREIRA, Daniel de Carvalho. Revisões sistemáticas da literatura: parte i. Parc Pesquisa em Arquitetura e Construção, [s.l.], v. 8, n. 3, p. 141, 31 jan. 2018. Universidade Estadual de Campinas. http://dx.doi.org/10.20396/parc.v8i3.8651561.

PARK, Sin-ae; SONG, Chorong; OH, Yun-ah; MIYAZAKI, Yoshifumi; SON, Ki-cheol. Comparison of Physiological and Psychological Relaxation Using Measurements of Heart Rate Variability, Prefrontal Cortex Activity, and Subjective Indexes after Completing Tasks with and without Foliage Plants. International Journal Of Environmental Research And Public Health, [s.l.], v. 14, n. 9, p. 1087, 20 set. 2017. MDPI AG. http://dx.doi.org/10.3390/ijerph14091087.

PARRIS, Kirsten M.; AMATI, Marco; BEKESSY, Sarah A.; DAGENAIS, Danielle; FRYD, Ole; HAHS, Amy K.; HES, Dominique; IMBERGER, Samantha J.; LIVESLEY, Stephen J.; MARSHALL, Adrian J.. The 
seven lamps of planning for biodiversity in the city. Cities, [s.I.], v. 83, p. 44-53, dez. 2018. Elsevier BV. http://dx.doi.org/10.1016/j.cities.2018.06.007.

PULIGHE, Giuseppe; FAVA, Francesco; LUPIA, Flavio. Insights and opportunities from mapping ecosystem services of urban green spaces and potentials in planning. Ecosystem Services, [s.l.], v. 22, p.1-10, dez. 2016. Elsevier BV. http://dx.doi.org/10.1016/j.ecoser.2016.09.004.

RICHARDS, Daniel; MASOUDI, Mahyar; OH, Rachel R. Y.; YANDO, Erik S.; ZHANG, Jingyuan; FRIESS, Daniel A.; GRêT-REGAMEY, Adrienne; TAN, Puay Yok; EDWARDS, Peter J.. Global Variation in Climate, Human Development, and Population Density Has Implications for Urban Ecosystem Services. Sustainability, [s.I.], v. $11, \quad$ n. $22, \quad$ p. 6200,6 nov. $2019 . \quad$ MDPI AG. http://dx.doi.org/10.3390/su11226200.

ROSSATTO, Davi Rodrigo; TSUBOY, Marcela Stefanini Ferreira; FREI, Fernando. ARBORIZAÇÃO URBANA NA CIDADE DE ASSIS-SP: UMA ABORDAGEM QUANTITATIVA. SBAU, Piracicaba, v. 3, n. 3, p.1-16, set. 2008

SACCHELLI, Sandro; FAVARO, Mirko. A Virtual-Reality and Soundscape-Based Approach for Assessment and Management of Cultural Ecosystem Services in Urban Forest. Forests, [s.I.], v. 10, n. 9, p. 731, 26 ago. 2019. MDPI AG. http://dx.doi.org/10.3390/f10090731.

SAMPAIO, R. F., MANCINI, M. C. Estudos de Revisão Sistemática: Um Guia Para Síntese Criteriosa Da Evidência Científica. Revista brasileira de fisioterapia, São Carlos, v. 11, n. 1, : 83-89, jan./fev. 2007.

SCOPUS. Analyze search results. 2020. Disponível em: https://bityli.com/NxPHL. Acesso em 11 julho 2020.

SETO, K. C.; GUNERALP, B.; HUTYRA, L. R.. Global forecasts of urban expansion to 2030 and direct impacts on biodiversity and carbon pools. Proceedings Of The National Academy Of Sciences, [s.l.], v. 109 , n. 40 , p. $16083-16088,17$ set. 2012. Proceedings of the National Academy of Sciences. http://dx.doi.org/10.1073/pnas.1211658109.

SETO, Karen C. et al. A Meta-Analysis of Global Urban Land Expansion. Plos One, [s.l.], v. 6, n. 8, p. 19, 18 ago. 2011. Public Library of Science (PLoS). http://dx.doi.org/10.1371/journal.pone.0023777.

TAVARES, Paulo Amador; BELTRÃO, Norma; GUIMARÃES, Ulisses Silva; TEODORO, Ana; GONÇALVES, Paulo. Urban Ecosystem Services Quantification through Remote Sensing Approach: a systematic review. Environments, [s.I.], v. 6, n. 5, p. 51, 9 maio 2019. MDPI AG. http://dx.doi.org/10.3390/environments6050051.

TEZA, Cláusio Tavares Viana; BAPTISTA, Gustavo Macedo de Mello . A Supressão de Vegetação e Redução da Área de Sequestro Florestal de Carbono na Área Metropolitana de Brasília. In: Rômulo José da Costa Ribeiro; Gabriela de Souza Tenorio; Frederico de Holanda. (Org.). Brasília: transformações na ordem urbana. 1ed.Rio de Janeiro: Letra Capital, 2015, v. 1, p. 285-302.

TRAN, Tyler J.; HELMUS, Matthew R.; BEHM, Jocelyn E.. Green infrastructure space and traits (GIST) model: integrating green infrastructure spatial placement and plant traits to maximize multifunctionality. Urban Forestry \& Urban Greening, [s.I.], v. 49, p. 126635, mar. 2020. Elsevier BV. http://dx.doi.org/10.1016/j.ufug.2020.126635.

UNITED NATIONS. World Urbanization Prospects 2018. 2018. Disponível em: https://population.un.org/wup/. Acesso em: 30 maio 2020. 
WANG, Haoluan; QIU, Feng. Spatial disparities in neighborhood public tree coverage: do modes of transportation matter?. Urban Forestry \& Urban Greening, [s.I.], v. 29, p. 58-67, jan. 2018. Elsevier BV. http://dx.doi.org/10.1016/j.ufug.2017.11.001.

WILLIS, Katherine J.; PETROKOFSKY, Gillian. The natural capital of city trees. Science, [s.l.], v. 356, n. 6336, p. 374-376, 27 abr. 2017. American Association for the Advancement of Science (AAAS). http://dx.doi.org/10.1126/science.aam9724.

WRÓ Y SKI, Rafał; SOJKA, Mariusz; PYSZNY, Krzysztof. The application of GIS and 3D graphic software to visual impact assessment of wind turbines. Renewable Energy, [S.L.], v. 96, p. 625-635, out. 2016. Elsevier BV. http://dx.doi.org/10.1016/j.renene.2016.05.016.

YAN, Yan; JIEYUAN, Zhu; GANG, Wu; YUNJUN, Zhan. Review and prospective applications of demand, supply, and consumption of ecosystem services. Acta Ecologica Sinica, [s.I.], v. 37, n. 8, p. 1-1, 2017. Acta Ecologica Sinica. http://dx.doi.org/10.5846/stxb201602010229.

YAN, Yan; WANG, Chenxing; QUAN, Yuan; WU, Gang; ZHAO, Jingzhu. Urban sustainable development efficiency towards the balance between nature and human well-being: connotation, measurement, and assessment. Journal Of Cleaner Production, [s.I.], v. 178, p. 67-75, mar. 2018. Elsevier BV. http://dx.doi.org/10.1016/j.jclepro.2018.01.013.

ZHENG, T.; YAN, Y.; LU, H.; PAN, Q.; ZHU, J.; WANG, C.; ZHANG, W.; RONG, Y.; ZHAN, Y.. Visitors' perception based on five physical senses on ecosystem services of urban parks from the perspective of landsenses ecology. International Journal Of Sustainable Development \& World Ecology, [s.I.], v. 27, n. $3, \quad$ p. 214-223, 20 fev. 2020. Informa UK Limited. http://dx.doi.org/10.1080/13504509.2020.1729272.

ZHOU, Yuerong; VARQUEZ, Alvin C. G.; KANDA, Manabu. High-resolution global urban growth projection based on multiple applications of the SLEUTH urban growth model. Scientific Data, [s.I.], v. 6, n. 1, p. 1-10, 18 abr. 2019. Springer Science and Business Media LLC. http://dx.doi.org/10.1038/s41597-019-0048-z.

ZHOU, Xiaolu; KIM, Jinki. Social disparities in tree canopy and park accessibility: a case study of six cities in illinois using gis and remote sensing. Urban Forestry \& Urban Greening, [s.I.], v. 12, n. 1, p. 88-97, jan. 2013. Elsevier BV. http://dx.doi.org/10.1016/j.ufug.2012.11.004.

ZHU, Zhe; ZHOU, Yuyu; SETO, Karen C.; STOKES, Eleanor C.; DENG, Chengbin; PICKETT, Steward T.a.; TAUBENBÖCK, Hannes. Understanding an urbanizing planet: strategic directions for remote sensing. Remote Sensing Of Environment, [s.l.], v. 228, p. 164-182, jul. 2019. Elsevier BV. http://dx.doi.org/10.1016/j.rse.2019.04.020.

\section{Vitor Hugo de Goes Sampaio}

Mestrando em Arquitetura e Urbanismo + Design pela Universidade Federal do Ceará - UFC, Especialista em Reabilitação Ambiental Sustentável Arquitetônica e Urbanística pela Universidade de Brasília - UnB (2020) e Engenheiro Ambiental e Sanitarista pelo Instituto Federal de Educação, Ciência e Tecnologia do Ceará - IFCE (2018) com período sanduíche no curso de Ciências Ambientais da Universitat Politècnica de València - UPV (2014 - 2015). No campo da pesquisa, foi Bolsista de Transferência Tecnológica (BTT) da Fundação Cearense de Meteorologia e Recursos Hídricos FUNCEME (2015 - 2019), mentor do Programa de Iniciação Científica do Cientista Beta (2017), bolsista CNPq do Programa Federal Ciência sem Fronteiras (2014 - 2015) e bolsista de Iniciação em Desenvolvimento Tecnológico e Inovação (PIBITI/CNPq) (2012 - 2014). Na área ambiental, foi estagiário na Estação de Tratamento de Águas Residuárias de Gandia (Valência, Espanha) (2015) e participou de 
Projetos Sociais voltados para a Educação Ambiental em Fortaleza e Região Metropolitana (2012 2014).

Contribuição de autoria: fundamentação teórico-conceitual e problematização; pesquisa de dados e análise estatística; elaboração de figuras e tabelas; Fotos; elaboração e redação do texto; seleção das referências bibliográficas; revisão do texto.

\section{Gustavo Macedo de Mello Baptista}

Professor Associado II do Instituto de Geociências da Universidade de Brasília. Coordenador do Pólo UnB do Mestrado Profissional em Rede Nacional para Ensino das Ciências Ambientais - ProfCiamb (2018 - atual). Ex-coordenador do Programa de Pós-Graduação em Geociências Aplicadas e Geodinâmica (2016 - 2018) e ex-Diretor do Centro de Estudos Avançados Multidisciplinares CEAM/UnB (2014 - 2016). Possui graduação em Bacharelado em Geografia pela Universidade de Brasília (1994), graduação em Licenciatura em Estudos Sociais - Habilitação Geografia pela União Pioneira de Integração Social Faculdades Integradas (2009), especialização em Inteligência de Futuro: Prospectiva, Estratégica e Políticas Públicas pela Universidade de Brasília (2015), mestrado em Tecnologia Ambiental e Recursos Hídricos pela Universidade de Brasília (1997) e doutorado em Geologia pela Universidade de Brasília (2001). Tem experiência na área de Geociências, com ênfase em Sensoriamento Remoto e em Avaliação Ambiental e Urbana. Pesquisador do Núcleo Brasília do INTC Observatório das Metrópoles.

Contribuição de autoria: revisão do método, conteúdo e texto.

Como citar: SAMPAIO, Vitor Hugo de Goes, BAPTISTA, Gustavo Macedo de Mello. Espaços verdes urbanos e as percepções globais dos serviços ecossistêmicos à luz da tecnologia. Revista Paranoá.n. 30, jan/jun 2021. DOI: http://doi.org/10.18830/issn.1679-0944.n30.2021.16

Editoras responsáveis: Carolina Pescatori, Dr. Daniel Sant'Ana e Caio Frederico e Silva. 